Available online at GSC Online Press Directory

GSC Biological and Pharmaceutical Sciences

e-ISSN: 2581-3250, CODEN (USA): GBPSC2

Journal homepage: https://www.gsconlinepress.com/journals/gscbps

(CASE REPORT)

\title{
Late complications of radiotherapy for breast cancer
}

\author{
Sofiane Kouas ${ }^{1,}{ }^{*}$, Naim Dhifaoui ${ }^{1}$, Khouloud Ikridih ${ }^{1}$, Sameh Mahdhi ${ }^{1}$, Ichrak Belghaieb ${ }^{1}$ and Anis Haddad ${ }^{2}$ \\ ${ }^{1}$ Department of Gynecology and Obstetrics, Monastir Medical School, Monastir University, Gynecology-Obstetric Service \\ Mahdia-Tunisia. \\ ${ }^{2}$ Department of Gynecology and Obstetrics, Monastir Medical School, Monastir University, El Omrane Hospital of Monastir- \\ Monastir-Tunisia.
}

Publication history: Received on 14 August 2020; revised on 07 September 2020; accepted on 09 September 2020

Article DOI: https://doi.org/10.30574/gscbps.2020.12.3.0266

\begin{abstract}
The late functional and aesthetic impact of breast neoplasia treatment partly reflects the consequences of high- dose irradiation of the skin and subcutaneous tissue. This work, based on a case observed in our department and a review of the literature, aims to discuss certain secondary manifestations following breast irradiation and their therapeutic options.
\end{abstract}

Keywords: Breast neoplasia; Radiotherapy; Treatment; Lymphedema.

\section{Introduction}

The assessment of the late effects of breast irradiation is justified by the frequency of breast neoplasias, the role of radiotherapy in their locoregional management and the importance of aesthetic outcomes in the assessment of the quality of care, especially after conservative treatment.

\section{Case presentation}

Our work reports the case of a premenopausal 46-year-old patient, sixth gesture fourth barrier, treated for a right breast neoplasia (figure 1) classified as T2 N1 M0.In July 2002; she underwent a Patey type mastectomy with axillary lymph node dissection. Histology substantiated the presence of an infiltrating ductal carcinoma SBR I of $2.8 \mathrm{~cm} 5 \mathrm{~N}+/ 13$. Mastectomy was followed by locoregional irradiation and adjuvant chemotherapy. Radiotherapy sessions ended in February 2003.

The subsequent course was marked by the appearance of cutaneous sclerosis (figure 2) affecting the right upper limb nerve root in April 2004 (13 months after the end of irradiation), significant lymphedema and clavicle fracture (figure 3). A bone scan ruled out a metastatic origin of the latter. For lymphedema, the patient underwent physiotherapy sessions without much improvement on the functional level.

\footnotetext{
${ }^{*}$ Corresponding author: Sofiane Kouas

Department of Gynecology and Obstetrics, Monastir Medical School, Monastir University, Gynecology-Obstetric Service MahdiaTunisia..
}

Copyright (C) 2020 Author(s) retain the copyright of this article. This article is published under the terms of the Creative Commons Attribution Liscense 4.0. 


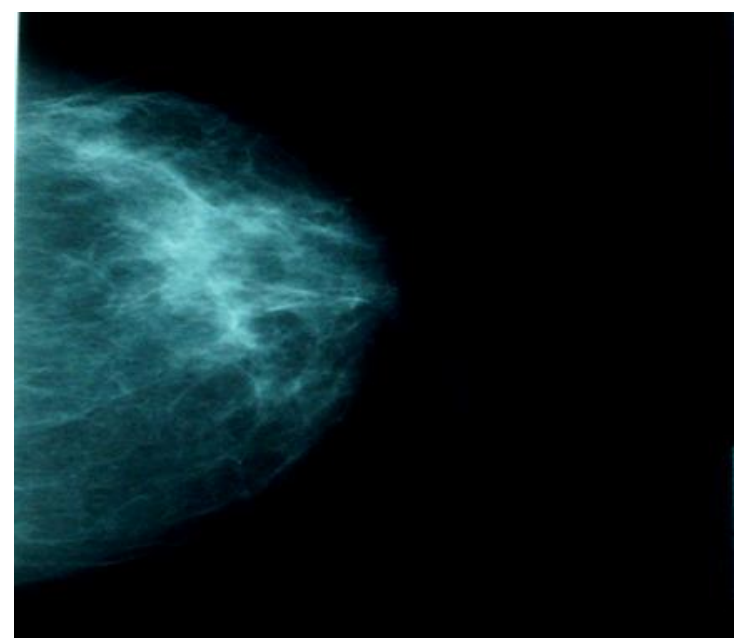

Figure 1 Mammographic image showing neoplasia of the breast.

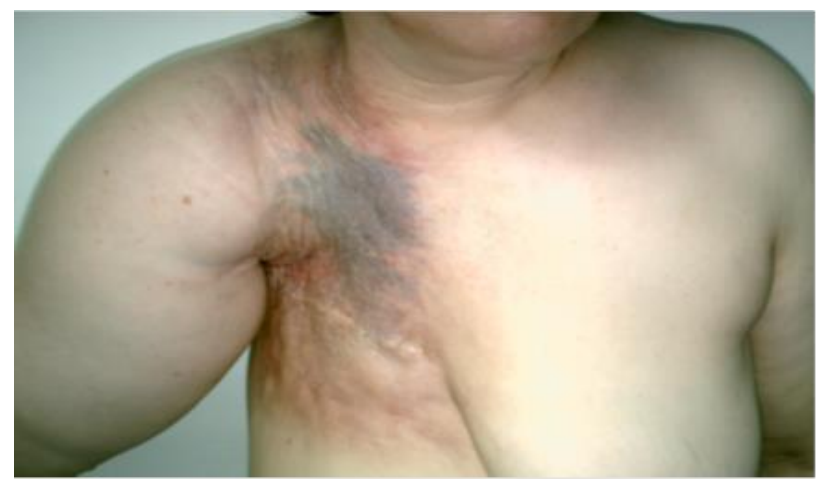

Figure 2 Photograph showing lymphedema and skin fibrosis

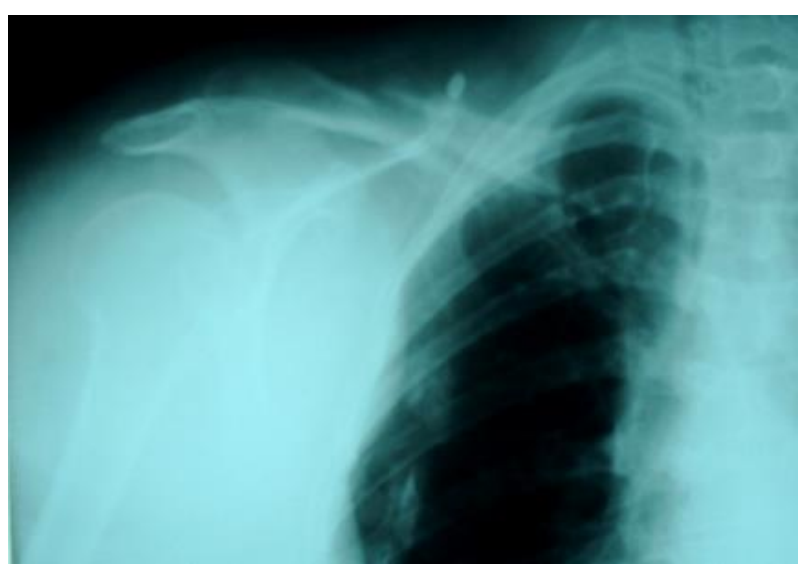

Figure $3 \mathrm{X}$-ray showing the non-metastatic fracture of the clavicle.

\section{Discussion}

Late cutaneous and subcutaneous manifestations induced by radiotherapy largely determine the aesthetic and functional outcome of the local treatment of breast tumors [1]. The Administration of a high dose to the skin is difficult to avoid due to its anatomical proximity to the target volume of radiotherapy. If irradiation is not the only determining factor, the technique and treatment methods can be adapted to limit the most harmful consequences [2].

Currently, various studies on the in vitro radiosensitivity of fibroblasts derived from patients treated with irradiation are in favor of a correlation between the radiosensitivity of these fibroblasts and the reactions of different healthy 
tissues to radiotherapy [4].Alsbeih et al [4] in their work on seven patients treated with radiation reported that this association suggests that the analysis of clonogenic survival, or a more convenient alternative, could be used as a predictive test. The involvement of several tissues and organs suggests the existence of genetic factors which determine, at least in part, the radiosensitivity of the target cells involved in the clinical phenotype of response to radiotherapy in these patients [4].However, given the small number and selection of patients included $(n=7)$, larger studies must be carried out to confirm these results [4].

The treatment of radiation-induced sequelae is classically disappointing, hence the idea deeply rooted in the minds of clinicians of their irreversibility and certain reluctance to engage in tiresome therapeutic trials. Several experimental studies andsome clinical studies: however, have indicated that certain treatments can be active on the fibrotic process. In the inflammatory phase, the transition to the stage of fibrosis could be prevented by the use of non-steroidal antiinflammatory drugs (NSAIDs). Corticosteroids, certain antiproliferative substances and phenotypic modulators of endothelial and connective cells (interferons) and low molecular weight heparins for antithrombotic purposes seem less active [2].

Different teams have also studied the incidence of lymphedema after radiosurgical treatment of breast neoplasia which varies between 0 and 73\% [3].The National Institute for Clinical Excellence in the UK, for example, reported an incidence of $25 \%$ to $28 \%$ and recommended its research 1 to 3 years after the establishment of the diagnosis [2].Lymphedema appears to be dependent on the type of surgery, adjuvant therapy, and the number of axillary nodes removed during the dissection. "Standard" axillary dissection appears to be responsible for lymphedema in $56 \%$ of cases.The use of less invasive methods such as the sentinel node technique seems to decrease its incidence [3].In a large prospective study including 1031 patients, Mansel [5] found a lymphedema risk reduction of up to 12 months after treatment. The relative risk was 0.37 (95\% confidence interval, 0.23-0.6) in favor of the sentinel node technique.

Axillary radiation therapy also appears to increase the risk of developing lymphedema in some studies. In fact, lymphedema occured in 23 to $58 \%$ of patients treated with axillary radiotherapy versus 5 to $12 \%$ only in those who had not received this treatment [3].On the contrary, a large randomized study found no relationship between breast radiotherapy and upper limb morbidity [3].Other risk factors are not well identified. Wounds and skin infections, as well as obesity, could stimulate the development of lymphedema. The latter is associated with a heavy morbidity such as mobility limitation and weakness of the limb, pain, and paraesthesia.

In a study carried out on 742 patients treated for breast neoplasia, Hiba et al [3] stated that $31.67 \%$ of their study population reported the appearance of lymphedema after an average interval of 4.3 years. The medical history of these patients included breast irradiation in all cases. They also reported that $44.3 \%$ of patients with a diagnosis of lymphedema experienced pain at the site of the intervention versus $36.9 \%$ of cases in those without lymphedema, in the armpit in $55.3 \%$ versus $31.8 \%$, in the arm in $57 \%$ versus $28.6 \%$, limitation of limb mobility in $63 \%$ versus $31.8 \%$, paresthesia in the armpit in $60.9 \%$ versus $36.1 \%$, and in the arm in $47.2 \%$ versus $23.5 \%$ of cases. The proportion of patients who reported these complications varied between 46 and $90 \%$.

Therapeutic options include massage, bandages, and physical exercise, often used in combination. Compression bandaging alleviates lymphedema by $39 \%$. Bandaging associated with an exercise program can reduce lymphedema by up to $50 \%$ [3]. A prospective randomized study showed that lymphatic drainage associated with compression was of little benefit only in cases of minimal lymphedema [6].The recommendations set out in the guidelines are to take good care of the limb by wearing gloves, for example, while doing house chores or gardening so as to avoid sores and skin infections [7].

\section{Conclusion}

The radiotherapist must adapt his prescription to minimize the sequelae and complications of the treatment without compromising tumor control. The development of rigorously evaluated effective therapies for subcutaneous fibrosis and lymphedema is indisputable.

\section{Compliance with ethical standards}

\section{Acknowledgments}

We thank all the authors who participated in this work which will serve as a reference for making future appropriate decisions. 


\section{Disclosure of conflict of interest}

The authors declare no conflict of interest.

\section{Statement of informed consent}

Informed consent was obtained from all individual participants included in the study.

\section{References}

[1] Carotte-Lefebvre I, Delaporte E, Mirabel X, Piette F. Complications cutanées de la radiothérapie (hors tumeurs malignes) Radiation-induced skin reactions (except cancers). Bull Cancer. 2003; 90(4): 319- 2.

[2] Dubray B, Delanian S, Lefaix JL. Effets Tardifs de la radiothérapie mammaire sur la peau et les tissus sous cutanés. Cancer/Radiother. 1997; 1: 744- 52.

[3] Hiba A, Bani HA, Fasching PA, Lux MM. et coll. Lymphedema in breast cancer survivors: Assessement and information provision in a specialized breast unit. Patient Education and counseling. 2007.

[4] Alsbeih G, Malone S, Grimard L, Raaphorst GP. La radiosensibilité in vitrodes fibroblastes de la peau peut identifier un groupe de patients ayant des complications dans différents tissues sains après radiothérapie. Cancer/Radiother. 1999; 3: 318-24.

[5] Mansel RE, Followfield L, Kissin M, Goyal A et coll. Randomized multicentric trial of centinel node biopsy versus standard axillary treatment in operable breast cancer: the ALMANAC trial. J Natl Cancer Inst. 2006;98:599-609.

[6] Balzarini A, Felisi E, Martini A, DeConno F. Efficacy of homeopathic treatment of skin reactions during radiotherapy for breast cancer: a randomized, double-blind clinical trial. British Homeopthic Journal. 2000; 89: 8-12.

[7] Ambrosone CB, Tian C, Ahn J, KroppSet coll. Genetic predictors of acute toxicities related to radiation therapy following lumpectomy for breast cancer: a case-series study.Breast Cancer Research. 2006; 8:R40. 